\title{
FACULTY SELF-ACTUALIZATION: Factors Affecting Career Success
}

\author{
Robert C. Cares, Siena Heights College \\ Robert T. Blackburn, Center for the Study of Higher Education, The \\ University of Michigan, Ann Arbor
}

This study determined the degree of relationship between four personal factors related to faculty growth and development, two environmental indices, and career success and satisfaction. Maslow's notion of self-actualization guided the construction of the personal indices of self-democraticness, support, tolerance, and trust; McGregor and Likert provided the theoretical bases for the environmental indices. The data came from the American Council on Education-Carnegie Commission national survey. Selecting only faculty at the rank of assistant professor and higher who were teaching in arts and science departments produced an $N$ of 7,534. Trust was the only personal variable significantly and consistently related to success and satisfaction, but even it had low contingency coefficients. Control of the work environment was the best predictor of the outcome variables and produced $\mathrm{CC}=0.41$ under certain conditions. While not a causal study, the findings nonetheless suggest that factors which can be more easily changed (environmental in contrast to personal) can positively affect faculty growth and development. Implications for administrators follow.

Key words: faculty; career; psychology

While the many colleges and universities that have recently launched faculty development programs have done so almost exclusively in the area of teaching (Gaff, 1975), certainly these programs have as their more comprehensive goal the aiding of academic people in achieving satisfying and successful careers along all dimensions of their work. As critical as the problem of faculty development is, little empirical data exist. Yet it is important to determine what personal and environmental factors are related to a professor's satisfying and successful career. What is needed is a large-scale analysis that will uncover the variables relating to a professors's self-actualization. This study removes a portion of the existing knowledge deficiency. 


\section{CONCEPTUAL FRAMEWORK}

Maslow's (1971) theoretical notion of self-actualization was employed to guide the construction of selected indices. Among Maslow's several factors postulated to be related to individual growth and development, and hence to career satisfaction and success, four were selected-selfdemocraticness, support, tolerance, and trust. As for the environmental factors, which could affect faculty growth and development and which would be open to institutional determination, two indices-the democraticness of the department and the opportunity for personal control of the work environment-were selected. McGregor (1960) and Likert (1961) provided the theoretical bases for the construction of the environmental indices. Both of their works were utilized by Maslow in the development of his ideas. The personal (Maslovian) and environmental indices were examined for their relationship to both satisfaction and success outcome measures.

\section{DATA}

The analysis utilized the data from the American Council on Education-Carnegie Commission (ACE-CC) 1969 survey of 100,315 faculty from 303 two-year, four-year, and research universities (Bayer, 1970 ). The $60 \%$ response rate was reduced to a one-third sample of approximately 20,000 , a number demonstrated by Trow (1972) to be representative of the total population. So as to maximize comparability, the principal analyses were further limited to white, male faculty with full-time appointments at the rank of assistant professor or higher with teaching appointments in liberal arts departments. This process produced an $N$ of 7,534 and represents the maximum sample (sometimes reduced because of unanswered items) for the principal analysis of the study.

\section{METHOD}

From the 287 data bits per respondent, four items were selected as independent success and satisfaction measures:

Level and Rank order point scoring

Question 37: Comparing yourself with other Success academic men of your age and qualification, how successful do you consider yourself in your career? 
Question 37: (Continued)

Level and Rank order point scoring

very successful

fairly successful

fairly unsuccessful

very unsuccessful $\}$

Question 38: In general, how do you feel about Good Place this institution?

It is a very good place for me It is a fairly good place for me

Question 39: Do you think you could be equally Satisfied or more satisfied with life in any

Here other college or university? definitely yes

probably yes

$\left.\begin{array}{l}\text { probably no } \\ \text { definitely no }\end{array}\right\}$

Question 40: If you were to begin your career Professor again, would you still want to be a college professor? definitely yes probably yes

$\left.\begin{array}{l}\text { probably no } \\ \text { definitely no }\end{array}\right\}$

Question 37 deals with success while 38 and 39 deal with satisfaction; question 40 could be classified as either success or satisfaction. (The combining of some responses in the scoring was done because of the low number of responses in one or the other or both categories.)

The Maslovian variable of Self-Democraticness was constructed from 
10 items that dealt with giving individuals the right to make and/or participate in decisions affecting their lives. Faculty were scored high on Self-Democraticness when they agreed with statements like "Most undergraduates are mature enough to be given more responsibility for their own education" and "A Student's grades should not be revealed to anyone off campus without his consent." Each index was initially constructed using face validity groupings. Intercorrelation matrices were run for each group. Factors having any correlation coefficient below the .20 level in an index group were not used in that index and were eliminated from the study unless they met the required criterion in another index group. This procedure was followed in constructing each index. Table 1, below, illustrates how six of the ten questions finally used in this index were selected. Cares (1975) provides extended data for each index.

The Tolerance index was constructed from seven items that dealt with respect for the rights of others. Persons received a high score on Tolerance when they agreed with statements that assured black control over their own schools where de facto segregation exists and when they thought that dissident groups contributed important criticisms of American culture. The Support index came from eight items that favored giving control in decision making to those who normally do not have it (e.g., undergraduates regarding disciplinary actions). The Trust index came from four questions that dealt with the credibility of the

TABLE 1. Correlation Coefficients for Construction of "Self-Democratic" Index

\begin{tabular}{|c|c|c|c|c|c|c|c|c|c|}
\hline & Variable & $19^{\mathrm{a}}$ & 36 & 38 & 107 & 110 & 189 & 246 & 281 \\
\hline $9 A^{a}$ & 19 & - & & & & & & & \\
\hline \multirow[t]{2}{*}{$9 \mathrm{~T}$} & 36 & .3504 & - & & & & & & \\
\hline & 38 & .2105 & .4185 & - & & & & & \\
\hline $27 Q$ & 107 & .2899 & .3919 & .1901 & - & & & & \\
\hline \multirow[t]{2}{*}{$27 \mathrm{~T}$} & 110 & .3523 & .4274 & .3509 & .5061 & - & & & \\
\hline & 189 & .3050 & .2562 & .2220 & .1939 & .3097 & - & & \\
\hline 58 & 246 & .3023 & .4117 & .2420 & .4619 & .4542 & .2471 & - & \\
\hline 74 & 281 & .2023 & .2850 & .0553 & .3722 & .2621 & .1245 & .3461 & - \\
\hline \multicolumn{10}{|c|}{$\mathrm{N}=869$} \\
\hline \multicolumn{10}{|c|}{$\mathrm{DF}=\mathbf{8 6 7}$} \\
\hline \multicolumn{10}{|c|}{$R @ .95=.0665$} \\
\hline \multicolumn{10}{|c|}{$\mathrm{R} @ .99=.0873$} \\
\hline
\end{tabular}

a The variable identifying numbers in the margin $(9 \mathrm{~A}$, etc.) refer to the original Carnegie Commission questionnaire. The vertical column numbers $(19,36$, etc.) below the word variable at the top refer to the author's coding system. Variables 38 and 189 did not meet the .20 criterion level. The relationships not meeting the criterion level are italicized. 
higher education system. Faculty were scored high in Trust when they disagreed with the statement that "many professors in graduate departments exploit their students to advance their own research" and that "many of the highest paid university professors get where they are by being 'operators' rather than by their scholarly or scientific contributions."

The environmental index of Department Democratic came from three items dealing with just that matter, viz., participation and voting by all. The Control of Environment index was constructed from six items that had to do with ability to influence policies and practices affecting their work-from controlling the courses they taught to influencing university policy decisions.

Preliminary chi-squares indicated variable associations. Intercorrelation matrices and contingency coefficients were then computed to identify the degree of the relationship between the variables and the outcome measures (satisfaction and success). Typical significance levels were utilized when interpreting the data.

\section{RESULTS}

With respect to the Masolvian variables, Tolerance, Self-Democraticness, and Support did not appreciably relate to the outcome measures of satisfaction and success. Of the personable variables, only Trust produced contingency coefficients in a consistent and statistically significant way. (See Table 2.) The more trusting individuals viewed their careers as more satisfying and as more successful. However, even here the contingency coefficients do not demonstrate a strong relationship.

The small but inverse relationships between Good Place, Tolerance, and Self-Democraticness, and the Success and Satisfaction variables raise the following questions: Do faculty who themselves are highly democratic, tolerant, and supportive have expectations of their environments which are unrealizable? Do faculty who are not as high on these characteristics possess more realizable (i.e., achievement) expectations?

Faculty who possess unrealizable expectations would find little opportunity for satisfaction or happiness. High democratic faculty, for instance, cannot be satisfied in what they perceive to be a nondemocratic environment. ${ }^{1}$ Very highly democratic faculty may wish for more convergence of their own values with those of the environment but in actuality are seeking what their environment is either unwilling or unable to provide. Faculty who are less democratic may more closely approximate a matching situation between their expectations and their environment. Less democratic faculty, therefore, at least have the possibility for satisfaction. 


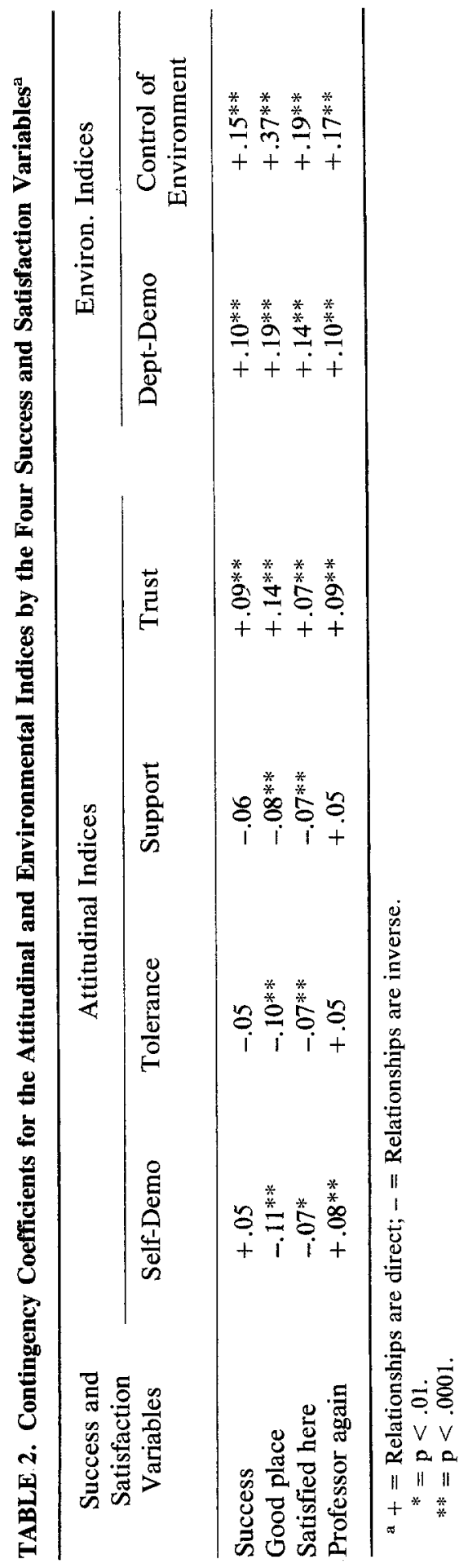


Also, the fit or lack of fit between expectations and actual experience probably has a direct bearing on feelings of control over one's environment. It is a complex and important interaction process. If one is tolerant, but working in an environment perceived to be intolerant, one is not likely to consider his environment "a good place for me," nor to be highly "satisfied." This disparate state is even more likely to the degree that tolerance is important to the respondent.

When only the "unsuccessful" and "unsatisfied here" answers were viewed, a trend appeared, viz., the lower the Tolerance scores were, the greater percentage of "unsuccessful" and "unsatisfied here" answers. The trend suggests the possibility that Tolerance is related differently to successful and satisfied perceptions than it is to unsuccessful and dissatisfied perceptions. That is, perhaps success and satisfaction are related to Tolerance in the way found by Herzberg, Mausner, and Snyderman (1959) in their study of engineers and accountants. Results of their study supported the two-factor theory of satisfaction and dissatisfaction developed in an earlier study by Herzberg et al. (1957). Essentially, the two-factor theory postulates two continua, one from satisfied to neutral and another from dissatisfied to neutral. Two-factor theory challenges the notion of one continuum, with satisfaction running through neutral to dissatisfaction. The contradictory results of the present study for the satisfied and successful answers contrasted with the dissatisfied and unsuccessful answers on Tolerance may be an example of the two-factor theory.

Also, the finding that highly democratic faculty felt they could be equally or more satisfied elsewhere and less democratic faculty felt they could not be equally or more satisfied at another college or university may be the effect of the relationship between democratic attitudes and flexibility, or the reverse relationship of more authoritarian attitudes with insecurity and rigidity, outcomes well documented by Adorno et al. (1950). The faculty who did not want to give responsibility to undergraduates and black students, who wanted to suspend students for disruptions and use of marijuana, who wanted to regulate student behavior off campus, who favored giving students' grades out without their consent, who were religiously conservative, who did not want students to evaluate them, and who felt that no other place could equal or surpass their present situation are the less democratic faculty in this study. The previously mentioned match or mismatch between expectations and realized experience in a particular environment is a second possible explanation for this finding.

As seen in Table 2, the most positive relationships occurred with perceived Democraticness of the department and the faculty member's Control of Environment. Control of Environment showed the highest 
relationship; the higher the environmental control, i.e., the more faculty felt they had control of the content of the courses they taught, that they had influence in both departmental and institutional policies, and that their administration supported academic freedom, the more satisfied and successful faculty judged themselves to be.

The importance of Control of Environment can be seen even more dramatically when a comparison is made where only those cases for the three highest levels of Self-Democratic and the two highest levels of Tolerance and Support were selected. This comparison (Table 3) shows that low Control of Environment faculty had a much larger percentage of "not Good Place" answers than expected when faculty were high on Self-Democratic, Tolerance, and Support, while the high Control of Environment faculty had more "Good Place" answers than expected. The 0.41 contingency coefficient shows the high strength of the relationship.

As for the generalizability of the results, the contingency coefficients in Table 4 show that in many instances it is important to control for individual and situational characteristics, especially on the environmental indices. With the exception of academic discipline and age for Dept-Democraticness, the environmental indices have CCs of .15 or higher. Older faculty express greater control of their work situations and are more likely to do so if they are at small, elite, nondenominational private colleges. On the other hand, faculty at large, public institutions perceived their departments to be the most democratic. The attitudinal indices require less control, except for age and field (academic discipline). Younger faculty are more Self-Demo, tolerant, and supportive than are their older peers. (Trust has low CCs with all characteristics.) Faculty who teach in the social sciences consistently score highest on the attitudinal indices with the humanities and natural sciences following in that order. See Cares (1975) for an expanded analysis.

\section{DISCUSSION}

A number of considerations suggest caution in interpreting the results of this study. First, the data were taken from a tape which had been designed to answer questions other than the ones this study investigated. The questions originally used were not specifically designed to study the concept of self-actualization and its relationship to success and satisfaction and therefore have limited applicability. Hence, the indices were approximations of the personal and environmental factors, not direct measures.

Second, this was an exploratory, rather than an experimental, de- 
TABLE 3. Comparison on Results for Contingency Tables on Control of Environment by Good Place and Control of Environment by Good Place Selecting for High Self-Demo, Tolerance, and Support ${ }^{\mathrm{a}}$

\begin{tabular}{|c|c|c|c|c|c|c|}
\hline \multirow[t]{2}{*}{$\begin{array}{c}\text { Control of } \\
\text { Environment }\end{array}$} & \multicolumn{3}{|c|}{ Good Place-All Cases } & \multicolumn{3}{|c|}{$\begin{array}{l}\text { Good Place Selecting } \\
\text { for High Self-Demo, } \\
\text { Tolerance, and Support }\end{array}$} \\
\hline & (1) & (2) & (3) & (1) & (2) & (3) \\
\hline $\begin{array}{l}\text { Expected \% } \\
\text { Levels }\end{array}$ & 48.9 & 43.1 & 8.0 & 41.0 & 46.0 & 13.0 \\
\hline (1) & 12.6 & 51.2 & 36.2 & 8.9 & 50.0 & 25.5 \\
\hline (2) & 25.1 & 54.6 & 20.3 & 23.4 & 51.0 & 25.5 \\
\hline (3) & 33.7 & 53.7 & 12.5 & 24.6 & 54.6 & 20.8 \\
\hline (4) & 43.5 & 50.0 & 6.6 & 39.3 & 54.4 & 6.3 \\
\hline (5) & 54.4 & 41.0 & 4.6 & 50.8 & 42.4 & 6.8 \\
\hline (6) & 62.6 & 35.0 & 2.4 & 61.8 & 35.5 & 2.7 \\
\hline \multirow[t]{2}{*}{ (7) } & 77.9 & 21.7 & 0.4 & 74.3 & 25.7 & 0.0 \\
\hline & \multicolumn{3}{|c|}{$\begin{array}{l}N=7082 \\
\mathrm{df}=12 \\
\mathrm{X}^{2}=1101 \\
p<.0001 \\
\mathrm{CC}=.37\end{array}$} & \multicolumn{3}{|c|}{$\begin{array}{l}N=1134 \\
\text { df }=12 \\
\mathrm{X}^{2}=231 \\
p<.0001 \\
\mathrm{CC}=.41\end{array}$} \\
\hline
\end{tabular}

a Column (1) is the percent who answered "my institution is a very good place for me";

(2) is the percent who answered "my institution is a fairly good place for me"; and

(3) is the percent who answered "my institution is not the place for me."

The levels came from the construction of the index. Respondents who scored only one item in the set composing the index in the high direction were placed at level 1, those who scored two questions in the high direction at level 2, and so forth.

For example, for all cases, $48.9 \%$ say their college or university is a very good place for them. However, when broken down by the Control of Environment the respondent expresses, this rises to $77.9 \%$ for those who have the highest level of environmental control and falls to $12.6 \%$ for those who say they have the lowest level of control. And when selecting only those faculty who score high on the importance of Self-

Democraticness, Tolerance, and Support (the right half of the table where the $N$ drops to 1,134 ), the same overall pattern is retained but the $C C$ increases to 0.41 . Less than one-half of $1 \%$ ( 0.4 for all cases and 0.0 for selected groups) who have the highest Control of Environment think where they now are is not the place for them.

sign. No notions of causality are intended. The study does not attempt to determine, for instance, if faculty see themselves as successful and satisfied because they feel they have control of the environment, or whether they feel that they have control because they see themselves as successful and satisfied. Similarly, the study does not attempt to sort out causes for the relationship between high Democraticness, Tolerance, Support, and Trust scores and high Dept-Democraticness and 


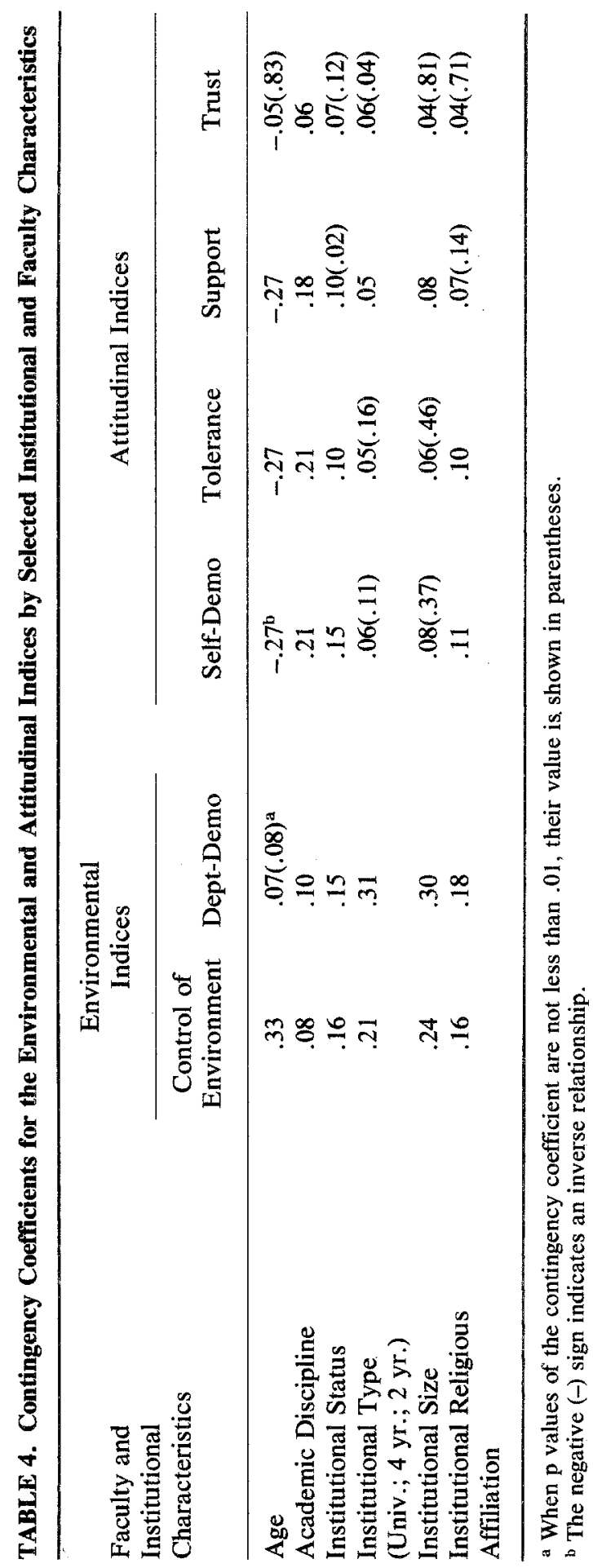


Control of Environment scores. The Inquiry determines relationships and comments upon their possible importance.

Third, there are other possible interpretations of the findings than those made here. For example, it is possible that faculty are successful for reasons other than those implied by the self-actualization process. At least three alternative explanations come to mind: (1) The psychological attributes related to success are permanent and basic individual characteristics. If a person possesses these attributes, he or she will be successful regardless of their source. If, on the other hand, the individual does not possess these attributes, he or she cannot become successful. (2) Success is situational, i.e., if the needs of the individual are well met by the significant others with whom interaction takes place, success will occur. If her or his needs are not met, he or she will not be successful. Said another way, the environment is the prime determiner and is amenable to alteration so that an unsatisfied individual can become successful. (3) Success is achieved by competition. The more able, stronger, and more ruthless scramble to the top, while the less able, weaker, and less competitive are pushed aside. Those who reach the top recognize they are successful and pay tribute to such variables as trust and control of environment.

The data in this study do not allow for separating one interpretation from another. Data on which faculty might fit a specific interpretation were not included on the original questionnaire. This exploratory inquiry cannot solve the dilemma.

The cautions discussed above call for modest interpretations of the data. In spite of their limitations, however, the findings appear to have important implications, which a unified interpretative view helps to clarify. Because the findings are based on a national random sample, they take on added importance. In addition, the Success and Satisfaction variables and the environmental indices, which are the component parts of the major findings of this study, do not share the definitional liabilities of the attitudinal indices.

One of the most consistent and significant findings of this study is that faculty who perceive their departments as democratic and who also have a high control of their environment score higher than the expected percentage for all four success and satisfaction variables. When the highly democratic faculty who also have high control of their environment are looked at, it is found that they have consistently higher percentages of Very Successful, Very Good Place, Very Satisfied Here, and positive Professor Again answers than were recorded by the total sample. Consistently higher percentages for all four attitudinal indices were also recorded when Dept-Democratic and Control of Environment scores were high. 
Control of the work environment appears to be the key variable in this study. In ways that could not have been anticipated, this variable has taken on central importance in understanding the relationships being studied. Its companion variable, Dept-Democraticness, may also be a measure of "control." Adler $(1973$, p. 67) states: "He (the individual) relates himself always according to his own interpretation of himself and of his present problem." The success perceptions in this study seem to touch on "his own interpretation of himself," while the "present problem" for faculty, and probably for all humans, centers around attempts to "control."

Maslow (1971, p. 14) pointed out the importance of freedom from control. He wrote: ". . . I can certainly say that descriptively healthy human beings do not like to be controlled. They prefer to feel free and to be free." Perhaps achieving or keeping control is synonymous with success for faculty in their work environment. This explanation seems particularly plausible as one reviews the factors which Maslow elaborated as descriptive of the self-actualization characteristics. In particular, he listed a liking for solitude, independence of the physical and social environment, inner detachment, and autonomy. None of these characteristics lend themselves easily to the process of being controlled. Add to this list the notions of play, creativity, spontaneity, and self-choice, and one wonders how a person who is becoming selfactualized could feel successful, satisfied, or happy if he perceives his environment as limiting his own control.

Maslow (1971, p. 208) was familiar with the management theories of both Likert and McGregor and referred his readers to their work. Maslow $(1971$, p. 282) felt that his nontranscending, "merely-healthy" self-actualizers met the expectations of McGregor's Theory Y, but the transcending self-actualizers "have not only fulfilled but also transcended or surpassed Theory Y." Maslow states: "They (the transcenders) live at a level which I shall here call Theory $Z$ for convenience and because it is on the same continuum as Theories $X$ and $Y$ and with them forms a hierarchy." It is central to Maslow's Theory $Z$ that the needs of the individual are more important than those of the organization.

Both Theory $\mathrm{X}$ and Theory $\mathrm{Y}$ are management systems designed to insure the "success of the enterprise." As McGregor (1960, p. 75) points out, ". . . the most important point with respect to management by integration and self-control is that it is a strategy-a way of managing people."' While the results of this study support McGregor's Theory $Y$, they seem to go beyond it and perhaps to challenge its orientation, at least as it relates to faculty and academic institutions. The central idea, which the present study supports, is that faculty do 
not want to be managed or controlled. In this study it was the degree of personal control of environment which related most significantly to faculty perceptions of success.

An academic institution differs in important ways from productoriented organizations. The full growth and development of human resources should be the major purpose of an educational institution as well as an integral part of its very processes.

On the practical side, those administering colleges and universities can benefit from these findings. Since the importance of perceived control of the environment and the democratic nature of the department fall within the administrative domain and are capable of alteration, it seems possible that increased satisfaction and success can be generated by the employment of democratic management principles. Successful faculty development programs need to pay attention to leadership and to the environment as much as they do to providing support for learning new teaching techniques.

Cause and effect were not determined in this inquiry, however. Future research needs to separate out what can be done with environmental considerations to increase success and to determine if critical personal characteristics are open to change.

\section{FOOTNOTES}

${ }^{1}$ This perception, which came late in the analysis process, is beyond the scope of this study. It appears to be a researchable question and should be observed where the attitudes of individual faculty and the environmental milieu are both known in order to see if, in fact, these are intolerant, autocratic, unsupportive places with respect to the fit with faculty expectations. Recent personal experiences have affirmed this interpretation.

\section{REFERENCES}

Adler, A. Superiority and social interest: $A$ collection of later writings. Heinz L. Ansbacher and Rowena Ansbacher (Eds.). New York: Viking Press, 1973.

Adorno, T. W., Frenkel-Brunswick E., Levinson, D. J., and Sanford, R. N. The authoritarian personality. New York: Harper Brothers, 1950.

Bayer, A. E. College and university faculty: A statistical description. American Council on Education Research Report, No. 5, Washington, D.C., 1970.

Cares, R. C. "Self-actualization attitudes of faculty and their perceptions of their career success." Unpublished Ph.D. dissertation, University of Michigan, 1975.

Gaff, J. G. Toward faculty renewal. San Francisco: Jossey-Bass, 1975.

Herzberg, F., Mausner, B., Peterson, R. O., and Capwell, D. F. Job attitudes: Review of research and opinion. Pittsburgh, PA: Psychological Service of Pittsburgh, 1957. 
Herzberg, F., Mausner, B., and Snyderman, B. The motivation to work (2nd ed.). New York: Wiley, 1959.

Likert, R. New patterns of management. New York: McGraw-Hill, 1961.

McGregor, D. The human side of enterprise. New York: McGraw-Hill, 1960.

Maslow, A. H. Toward the farther reaches of human nature. New York: The Viking Press, 1971. 